\title{
GOLBADODER \\ Cftr affects gallbladder function and bile acid homeostasis
}

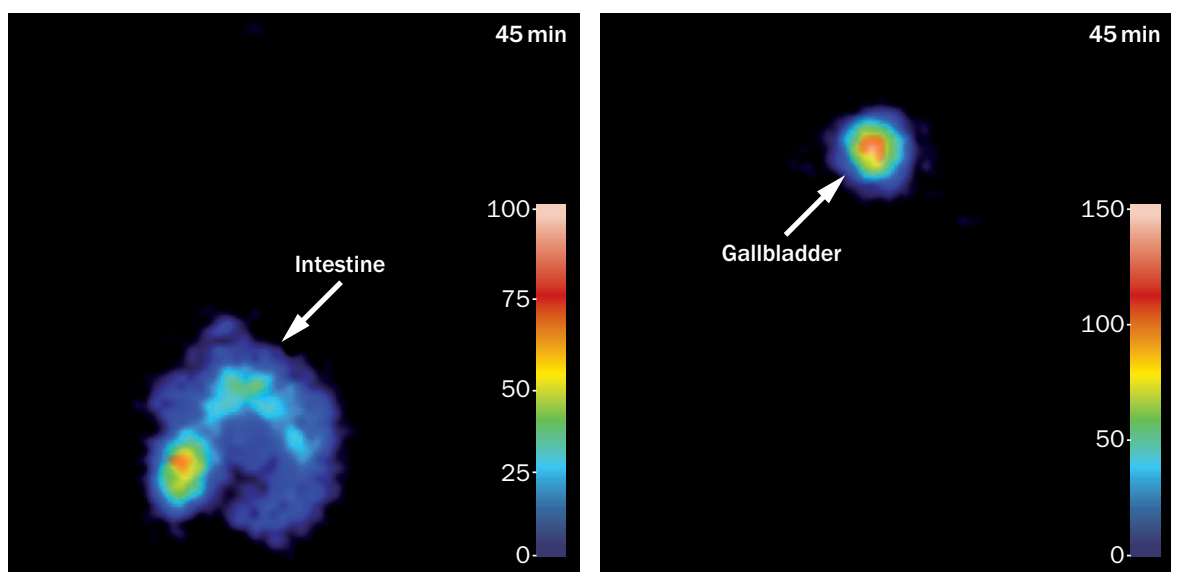

Scintigraphic images of mouse gallbladder function. ${ }^{99 m} \mathrm{Tc}-$ mebrofenin was secreted from the gallbladder into the duodenum in wild-type mice (left) but was retained in the gallbladders of $\mathrm{Cftr}^{\prime-}$ mice (right). Image produced in association with C. Housset.

Mice lacking cystic fibrosis transmembrane conductance regulator ( $C f t r)$ expression have impaired gallbladder emptying and bile acid homeostasis say French scientists.

Gallbladder motor function was examined in wild-type and $\mathrm{Cftr}^{-/-}$mice, using a radiotracer. "This is the first time that ${ }^{99 \mathrm{~m}} \mathrm{Tc}$-mebrofenin hepatobiliary scintigraphy has been used to assess gallbladder function in a small animal model," explains Chantal Housset, lead investigator at INSERM, France. Hepatocytes take up the tracer and then secrete it in bile-initial accumulation in the gallbladder shows normal liver function. After $45 \mathrm{~min}$, the tracer had been secreted into the duodenum in wild-type but not $\mathrm{Cftr}^{-/-}$mice, indicating gallbladder dysfunction.

The researchers suggest that impaired gallbladder emptying can disrupt enterohepatic circulation of bile acids but that a cholecystohepatic shunt maintains cycling through the liver. In patients with cystic fibrosis, this disruption in enterohepatic circulation might contribute to fat malabsorption, reduce the levels of secondary bile acids in the intestine and alter the composition of the intestinal microbiota.

"The next step is to understand links between bile acid homeostasis, the microbiota and the integrity of liver tissue," says Housset.

\section{Andy McLarnon}

Original article Debray, D. et al. Defects in gallbladder emptying and bile acid homeostasis in mice with cystic fibrosis transmembrane conductance regulator deficiencies. Gastroenterology doi:10.1053/j.gastro.2012.033 